Rapid Reviews COVID-19

\title{
Reviews of "Herd \\ immunity thresholds for \\ SARS-CoV-2 estimated \\ from unfolding epidemics"
}

Keith Klugman ${ }^{1}$, Pieter Trapman ${ }^{2}$

${ }^{1}$ Pneumonia Program Strategy Team, Bill and Melinda Gates Foundation,

${ }^{2}$ Senior Lecturer, Mathematics, Stockholm University: Stockholms Universitet, Sweden

Published on: Nov 17, 2020

DOI: $10.1162 / 2 e 3983 f 5 . b 8299664$

License: Creative Commons Attribution 4.0 International License (CC-BY 4.0). 
To read the original manuscript, click the link above.

Summary of Reviews: Reviewers find that this study presents important concepts surrounding heterogeneous transmission rates and their effects on herd immunity thresholds, but suggest that there are major flaws in the modeling assumptions that produce misleading results.

\title{
Reviewer 1 (Keith Klugman) | प्र००
}

\section{Reviewer 2 (Pieter Trapman) |}

\author{
RR:C19 Strength of Evidence Scale Key

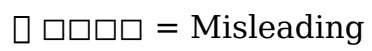 \\ प्र प्र = Not Informative \\ प्रा पि = Potentially Informative \\ प्र०प्र = Reliable \\ प्साप्र = Strong
}

To read the reviews, click the links below. 